\title{
Latent Chronic Kidney Disease (CKD) Manifesting as Eclampsia in Elderly Primigravida
}

\author{
Kirti Singh ${ }^{1}$, Neema Acharya ${ }^{2}$, Sourya Acharya ${ }^{3}$, Mohit Agrawal $^{4}$ \\ 1, 2, 4 Department of Obstetrics and Gynaecology, Jawaharlal Nehru Medical College, AVBRH, \\ DMIMS, Sawangi, Wardha, Maharashtra, India. ${ }^{3}$ Department of General Medicine, Jawaharlal \\ Nehru Medical College, AVBRH, DMIMS, Sawangi, Wardha, Maharashtra, India
}

\section{INTRODUCTION}

We present here a case of elderly primigravida aged 36 years with 35 weeks GA (Gestational Age) who came with seizures. Patient was later diagnosed with chronic kidney disease which led to uremic encephalopathy causing seizures, which was mistaken to be eclampsia.

Advanced maternal age during pregnancy can be associated with several complications like diabetes, hypertension and chromosomal defects. As the age increases, women are at increased risk of adverse maternal and perinatal outcome. Any comorbidities if present should be detected in early pregnancy, to avoid complications at the time of delivery.

In pregnancy, systemic vascular resistance and mean arterial pressure decreases, whereas, there is increase in cardiac output increases. There is vasodilatation of the collecting system and the renal size increases causing increase in renal plasma flow and hence the Glomerular Filtration Rate (GFR), with lower plasma osmolality and mild hyponatremia. These renal changes are essential for an optimal pregnancy outcome.1,2 Although serum creatinine is the most important predictor for pregnancy outcome in CKD women, it is not significant in mild and moderate renal impairment.

Many diseases can lead to end stage renal disease, these include, diabetes, glomerulonephritis and polycystic kidney disease. Prognosis of pregnancy outcome depends on amount of impairment one has. These include normal or mild impairment which is defined as a serum creatinine $<1.5 \mathrm{mg} / \mathrm{dL}$; moderate impairment defined as a serum creatinine 1.5 to $3.0 \mathrm{mg} / \mathrm{dL}$; and severe renal insufficiency-defined as a serum creatinine $>3.0 \mathrm{mg} / \mathrm{dL}$.

Eclampsia is a severe complication of preeclampsia presenting as generalized tonic clonic convulsions. Eclampsia is most common in the last trimester and becomes increasingly frequent as term approaches. Target organ for the mechanisms responsible for preeclampsia-eclampsia is kidney. Renal involvement, rarely presents as acute renal failure. ${ }^{3}$

\section{PRESENTATION OF CASE}

A 36-year-old primigravida, at 35 weeks GA presented with drowsiness, indicative of postictal phase, with history of 3 episodes of seizures. Patient was found to be hypertensive (BP: 160 / $100 \mathrm{mmHg}$ ) and had pedal oedema and abdominal oedema on examination. All findings of initial investigations revealed the following reports, Hb: 10.2 g \%, WBC: 7800 / cu mm, PLT: 90000, AST: 102 mg / dL, ALT: 116 mg / dL, Serum Uric acid: $5 \mathrm{mg} / \mathrm{dL}$, serum. LDH: $700 \mathrm{mg} / \mathrm{dL}$, serum. Urea: $100 \mathrm{mg} / \mathrm{dL}$, serum. creatinine: $4.2 \mathrm{mg} / \mathrm{dL}$, S. Potassium: $5.2 \mathrm{mmol} / \mathrm{L}$ and Serum sodium: 136 mmol / L. On dipstick: $2+$ proteinuria was found.
Corresponding Author:

Dr. Kirti Singh,

Department of Obstetrics and Gynaecology, Jawaharlal Nehru Medical College, AVBRH, DMIMS, Sawangi, Wardha, Maharashtra, India.

E-mail: contact.kirtisingh@gmail.com

DOI: $10.14260 / \mathrm{jemds} / 2020 / 790$

How to Cite This Article:

Singh K, Acharya N, Acharya S, et al. Latent chronic kidney disease (ckd) manifesting as eclampsia in elderly primigravida. J Evolution Med Dent Sci 2020;9(47):35963597, DOI: 10.14260/jemds/2020/790

Submission 29-05-2020,

Peer Review 07-10-2020,

Acceptance 14-10-2020,

Published 23-11-2020.

Copyright (c) 2020 Kirti Singh et al. This is an open access article distributed under Creative Commons Attribution License [Attribution 4.0 International (CC BY 4.0)] 
The patient was a booked case, and gave history of being hypertensive since 28 weeks of GA. Patient gave history of taking Tablet. labetalol $100 \mathrm{mg}$ BD since then. Patient was catheterized. Patient was administered injection magnesium sulphate 4gm in drip over 20 mins. Seizures subsided. Again, after 2 days, patient had 2 episodes of seizures. Her BP was not raised. Lab reports suggested Serum creatinine to be increased to $5.8 \mathrm{mg} / \mathrm{dL}$, Serum urea $120 \mathrm{mg} / \mathrm{dL}$, Serum Potassium: 6 mmol / l. Ph: 7.1, PCO2: 35 mmHg, HCO3: 12L, 02 sat: $99 \%$. Patient's ultrasound was done, which revealed bilateral kidney showing raised cortical echogenicity with loss of corticomedullary differentiation, s / o Grade 3 Renal parenchymal disease. Lab reports and ultrasound findings, cumulatively suggested that the patient was suffering from chronic kidney disease, which in due process of pregnancy caused acute kidney injury.

Thus, due to chronic renal failure, patient developed metabolic acidosis along with uremic encephalopathy causing seizures. Patient underwent three cycles of haemodialysis. Her creatinine level came down to $3 \mathrm{mg} / \mathrm{dL}$ and Serum urea to 48 $\mathrm{mg} / \mathrm{dL}$ and Serum Potassium: $4.5 \mathrm{mmol} / \mathrm{L}$. Patient was taken for caesarean section and a healthy baby, female, $2.4 \mathrm{~kg}$ was delivered. Mother and baby both were in good health. No further episode of seizure occurred. Patient BP was maintained and was discharged on $6^{\text {th }}$ day postoperative day after suture removal.

\section{DISCUSSION}

Patients presenting with renal failure, commonly, encephalopathy is seen. This can be due to several causes including vitamin B1 deficiency, transplant rejection, hypertension, fluid and electrolyte imbalance or renal dialysis. $^{4}$ In encephalopathy, patients presents with a symptoms progressing from mild sensorial clouding to delirium and coma. In our patient, there was no such episode. She developed flaps along with convulsions. The pathophysiology behind uremic encephalopathy up to now is uncertain, but several factors are involved, ${ }^{5}$ it is a complex and probably multifactorial process. The contributing factors are accumulation of metabolites, oxidative stress and imbalance in neurotransmitters. ${ }^{6}$

Uremic encephalopathy's symptoms are more profound and progresses more readily in acute renal failure compared to chronic renal failure. 7,8

In this case, patient was hypertensive, was misleading in our diagnosis.

Patient presented with seizures along with high BP, which made our diagnosis to be eclampsia. But with antihypertensives, we were not able to control the seizures and the renal function test continued to deteriorate. This led us to think of some other underlying condition, which was hidden. Thus we considered doing ultrasound to rule out some systemic complications which can be additive because of advanced maternal age. In higher stages of CKD, postpartum renal deterioration is more and there is more progression to end stage renal disease.

Uremic encephalopathy responded very efficiently to haemodialysis in this patient. Patient was saved as correct diagnosis was made with help of both ultrasound and clinical findings.

\section{CONCLUSIONS}

Latent chronic kidney disease can manifest as eclampsia by developing acute renal failure causing uremic encephalopathy.

Hence, both ultrasound and clinical findings should be correlated so that we can come out with the correct diagnosis and correct measures can be taken to prevent it.

Financial or other competing interests: None.

Disclosure forms provided by the authors are available with the full text of this article at jemds.com.

\section{REFERENCES}

[1] Maynard SE, Thadhani R. Pregnancy and the kidney. J Am Soc Nephrol 2009;20(1):14-22.

[2] Williams D, Davison J. Chronic kidney disease in pregnancy. BMJ 2008;336(7637):211-6.

[3] Grunfeld JP, Ganeval D, Bournerias F. Acute renal failure in pregnancy. Kidney Int 1980;18(2):179-91.

[4] Mahoney CA, Arieff AI. Uremic encephalopathies: clinical, biochemical, and experimental features. Am J Kidney Dis 1982;2(3):324-36.

[5] Fraser CL, Arieff AI. Metabolic encephalopathy as a complication of renal failure: mechanisms and mediators. New Horiz 1994;2(4):518-26.

[6] Vanholder R, De Smet R, Glorieux G, et al. Review on uremic toxins: classification, concentration, and interindividual variability. Kidney Int 2003;63(5):193443.

[7] Raskin NH. Neurological complications of renal failure. In: Aminoff MJ, ed. Neurology and general medicine. $2^{\text {nd }}$ edn. New York: Churchill Livingstone 1995:303-19.

[8] Burn DJ, Bates D. Neurology and the kidney. J Neurol Neurosurg Psychiatry 1998;65(6):810-21. 